\title{
Motor neuron disease in England and Wales, 1959-1979
}

\author{
JONATHAN BUCKLEY,* CHARLES WARLOW, PETER SMITH, \\ DAVID HILTON-JONES, SYLVIA IRVINE, † JAMES R TEW
}

From the Department of Community Medicine and General Practice and of Clinical Neurology, University of Oxford, and the Department of Medical Statistics and Epidemiology, London School of Hygiene and Tropical Medicine, London

SUMMARY Mortality rates from motor neuron disease in England and Wales for the years 19591979 were studied through death certification data supplied by the Office of Population Censuses and Surveys. The age- and sex-adjusted mortality rate increased over the period from 1.2 per 100000 per year in 1959-61 to 1.6 in 1977-79, the increase being most apparent in women over age 45 years and men over 60 years. The ratio of the sex-specific mortality rates remained fairly constant at 1.6:1 (male to female). The distribution of motor neuron disease deaths within England and Wales showed more variation between counties and between Hospital Regions than expected, and areas of high motor neuron disease mortality along the south coast and low mortality in the Midlands could be identified. The variation was most marked in those aged over 65 years at death. Examination of occupation, as listed on the death certificates, showed an excess of motor neuron disease deaths in leather workers in all three periods for which data were available (1959-63. 1970-72 and 1975). A small study of the certified cause of death of 56 motor neuron disease patients showed that a high percentage $(88 \%)$ had motor neuron disease given as the cause of death.

Approximately one in a thousand deaths in England and Wales are caused by motor neuron disease. The course of the disease is fairly rapid with death occurring usually within 3-5 years of onset. Several variants are recognised: progressive muscular atrophy, when the disease is confined to the anterior horn cells of the spinal cord, progressive bulbar palsy, when the cranial motor nuclei are primarily involved and amyotrophic lateral sclerosis when there is pyramidal involvement. In the United States, the generic name amyotrophic lateral sclerosis is preferred to motor neuron disease.

Despite the apparent simplicity of the pathological process in motor neuron disease, there is an almost complete lack of knowledge of its cause, or of any way of slowing or arresting the progress of the disease. Many factors have been reported in association with

*Address for reprint requests: Department of Family and Preventive Medicine. University of Southern California, 2025 Zonal Avenue. Los Angeles, California 90033, USA.

$\doteqdot$ Deceased

Received 2 September 1982. Accepted 4 October 1982 motor neuron disease, but usually in small series of cases. These have included exposure to lead, ' organic compounds of mercury, 2 manganese, 3 selenium, 4 pneumatic drilling, ${ }^{5}$ heavy labour, ${ }^{6}$ mechanical injuries, ${ }^{1} 78$ electric shock, ${ }^{9}$ spinal anaesthesia, ${ }^{10}$ and various diseases including malignant neoplasia ${ }^{11}$ and poliomyelitis. ${ }^{12}$ One of the few large studies compared 504 male cases among World War II army veterans in the United States with matched controls, using data collected at induction or during wartime service. $x$ Significantly more cases than controls reported a history of trauma or surgery before entering military service, and cases had significantly more trauma, particularly limb fracture, during their service.

The dearth of information about the disease and its aetiology prompted Sylvia Irvine, a motor neuron disease sufferer and co-author of this paper. to conduct a study of motor neuron disease in England and Wales with the help of JR Tew. The present study has grown out of their initial work on motor neuron disease mortality patterns and looks particularly at secular trends, regional variations and occupational associations. 


\section{Methods}

Mortality rates from motor neuron disease were calculated from data supplied to us by the Office of Population Censuses and Surveys (OPCS) or obtained from OPCS publications. ${ }^{13}$ The ICD rubrics of 356 ( 7 th Revision), 348 (8th Revision, used by OPCS from 1968 to 1978) and 335 (9th Revision, introduced in 1979) include the spinal muscular atrophies as well as the diseases of interest, progressive muscular atrophy, bulbar palsy and amyotrophic lateral sclerosis. After exclusion of cases aged under 30 years, however, these three digit rubrics adequately define the adult forms of motor neuron disease. Only deaths for which motor neuron disease was classified as the "underlying cause" have been supplied to us by OPCS, so that patients with motor neuron disease whose deaths were certified as due to another cause have been excluded from our analyses.

To check on the accuracy of death certification, we identified as many patients as possible who presented to hospitals in Oxfordshire and Berkshire between January 1974 and December 1978, in whom a clinical diagnosis of motor neuron disease had been made. Case notes for these patients were traced from the records of the individual consultant neurologists in the Oxford area, from the records of Dr G Rushworth in the Neurophysiology Department in Oxford and through the Oxford Record Linkage System. Over 100 sets of case notes were examined and it was possible to identify 72 patients in whom the diagnosis of motor neuron disease appeared certain.

Secular Trends Deaths from motor neuron disease in England and Wales from 1959-1979, classified by age and sex, were used with corresponding population figures to estimate age- and sex-specific mortality rates. A moving average (over three consecutive years) was used to smooth the graphed mortality rates and the overall mortality rate for each year was standardised to the 1971 population using the direct method.

Regional Variations Deaths from motor neuron disease in England and Wales from 1975-77, classified by age, sex and district, and their corresponding population bases, were obtained from OPCS. There are 381 districts (or municipal boroughs) in England and Wales which can be grouped into 54 counties. The observed deaths in each area-district or county $\left(\mathrm{O}_{\mathrm{i}}\right)$ was compared with an expected number of deaths $\left(E_{i}\right)$ assuming no regional variation, and the standardised mortality ratio for the area $\left(=\frac{O_{i}}{E_{i}} \times 100\right)$ and a test of significant (non-random) variation between areas (the sum of $\left(\mathrm{O}_{\mathrm{i}}-\mathrm{E}_{\mathrm{i}}\right)^{2} / \mathrm{E}_{\mathrm{i}}$ for all areas) were calculated.

Data were also available on age- and sex-specific mortality rates in England and Wales by Hospital Region (of which there are 15) from 1963-1973. These were analysed in the same way as the district and county figures for the years 1963-66, 1967-70 and 1971-73 and the results pooled.

The numbers of neurologists and neuropathologists in each county were obtained from the membership list of the Association of British Neurologists and the relationship between the standard mortality ratio in each county and this estimate of availability of specialist neurology consultants was assessed by the Kendall test of rank correlation.

The clustering of high and low standardised mortality ratios in different areas of England and Wales was tested for significance by the method suggested by Ohno et al. 14

Occupational Mortality The occupation given on the death certificate is coded and made available by OPCS only for a census year and the years on either side of the census. An exception to this was in 1975 when all occupations were coded in anticipation of a possible mid-decade census in 1976. We obtained the detailed listing of deaths from motor neuron disease in 1975 and compared the number of cases aged 30-74 in each Occupation Order with an expected number based on the proportion of the general population in each Order as determined at the 1971 census. Observed and expected deaths in 1970-72 for each Occupation Order for men aged 30-64 years were also available from OPCS and these were combined with the 1975 figures.

\section{Results}

\section{Accuracy of death certification}

Of the 72 patients from Oxfordshire and Berkshire who had well-documented motor neuron disease, eight could not be traced through the National Health Service Central Register. A further eight patients were known to be alive at the time information was requested (September 1981). For the 56 patients known to have died, motor neuron disease was recorded on Part 1 of the death certificate ("underlying cause") for 49 patients $(87.5 \%)$ and on Part 2 ("contributing factor") for four patients. In three instances motor neuron disease was not recorded on the death certificate-in one, the cause of death had been initially given as motor neuron disease, but changed to cerebral infarction after a post mortem examination.

\section{Mortality rates and secular trends}

The age- and sex-specific mortality rates averaged

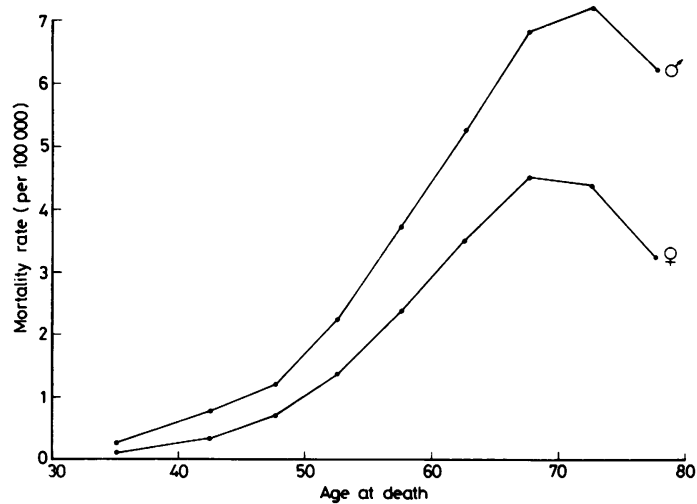

Fig 1 Age-and sex-specific mortality rates from motor neuron disease averaged over the years 1959 to 1979. 
over the period 1959 to 1979 are shown in fig 1 . The male to female ratio remained fairly constant, at about $1 \cdot 6$ to 1 between the ages of 45 and 74 years. The ratio was higher for those aged 75 years or over ( 1.9 to 1$)$ and for those aged below 45 years $(2.4$ to 1$)$, but diagnostic uncertainties in the oldest age group and the very small number of cases under age 45 years make both these ratios unreliable.

There has been a gradual increase in motor neuron disease mortality rates over the last 20 years as can be seen from fig 2. Each point in this figure is the average rate for three consecutive years. The upward trend is apparent for both sexes but is more marked in females, so that from 1960 (actually an average over 1959-61) to 1978 (averaged 1977-79) the male to female ratio for the whole population decreased from $1 \cdot 38$ to 1 to $1 \cdot 18$ to 1 . The graphs of moving averages of the age- and sex-specific rates are shown in figs 3

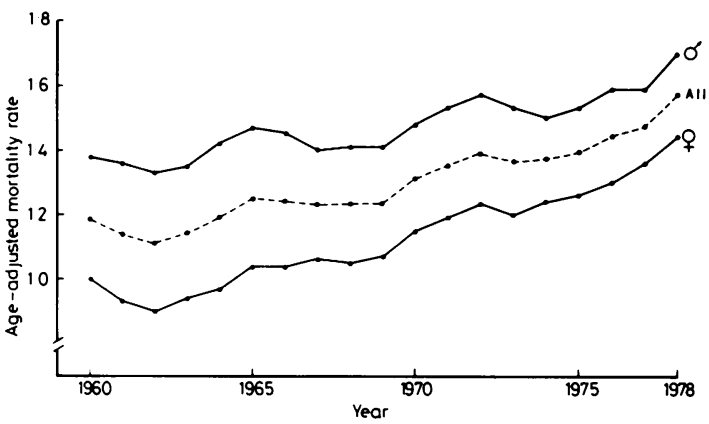

Fig. 2 3-year moving average of age-adjusted mortality rates for motor neuron disease in England and Wales over the period 1959 to 1979. (Standardised to the 1971 population of England and Wales.)

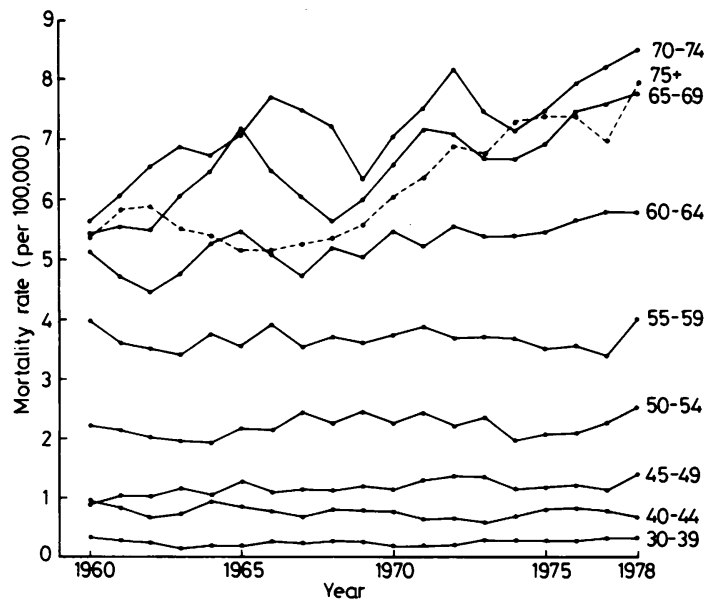

Fig 3 3-year moving averages of age-specific motor neuron disease mortality rates for males in England and Wales. The line for $75+$ is dashed for clarity. and 4. The increases are most apparent in those aged over 60 years in both sexes but the increase in motor neuron disease death rates in women aged 45-60, although smaller in absolute terms, represented a similar percentage change $(35-45 \%)$.

\section{Regional variations}

The standardised mortality ratios for the 54 counties in England and Wales in 1975-77 are listed in table 1. In view of the small number of motor neuron disease deaths in most counties, the calculated standardised mortality ratios had wide confidence limits. However, there was statistically significant variation in the standardised mortality ratios between counties for all aged 30 or more $(p=0.006)$ and for those aged 65 years or more $(p<0.001)$ but not for those aged 30 to 64 years $(p=0 \cdot 7)$. A cluster of counties with a high standardised mortality ratio was apparent along the southern coast and a region of below average mortality extended through South Wales and the Midlands (fig 5). The cluster pattern failed to reach statistical significance by the method of Ohno et allt $(p=0 \cdot 14)$, which tests for an increase over chance in the number of pairs of adjacent counties with a standardised mortality ratio in the same grouping (the standardised mortality ratio groups used were $<85$, 85-94, 95-105, 106-115 and >115).

One possible explanation for variations between counties is that the diagnosis is made more often in those counties with the best medical services, or more particularly, with the most neurologists. An estimate of the number of neurologists per 100000 population in each county is given in table 1 . It can be seen that some counties with high standardised mortality ratios such as Oxfordshire, Tyne and Wear, and Surrey are well served with neurologists while some areas with low motor neuron disease mortality rates (Salop, Clwyd and Lincolnshire for example) have no neurol-

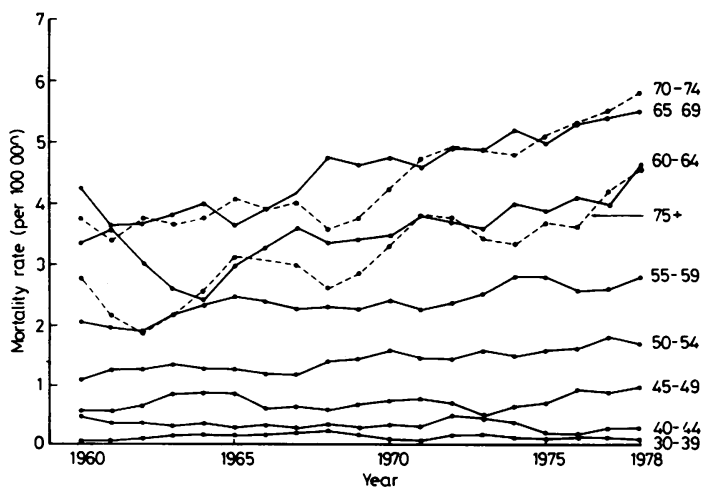

Fig 4 3-year moving averages of age-specific motor neuron disease mortality rates for females in England and Wales.

The lines for 70-74 and 75+ are dashed for clarity. 
Table 1 Standardised motor neuron disease mortality ratios for each county for all deaths in 1975-77 at age 30 years or more, for deaths at ages 30-64 years, for ages 65+ years, for males and for females. The observed numbers of deaths in each category are given in brackets. Also tabulated are the number of members of the Association of British Neurologists per 100000 population in each county

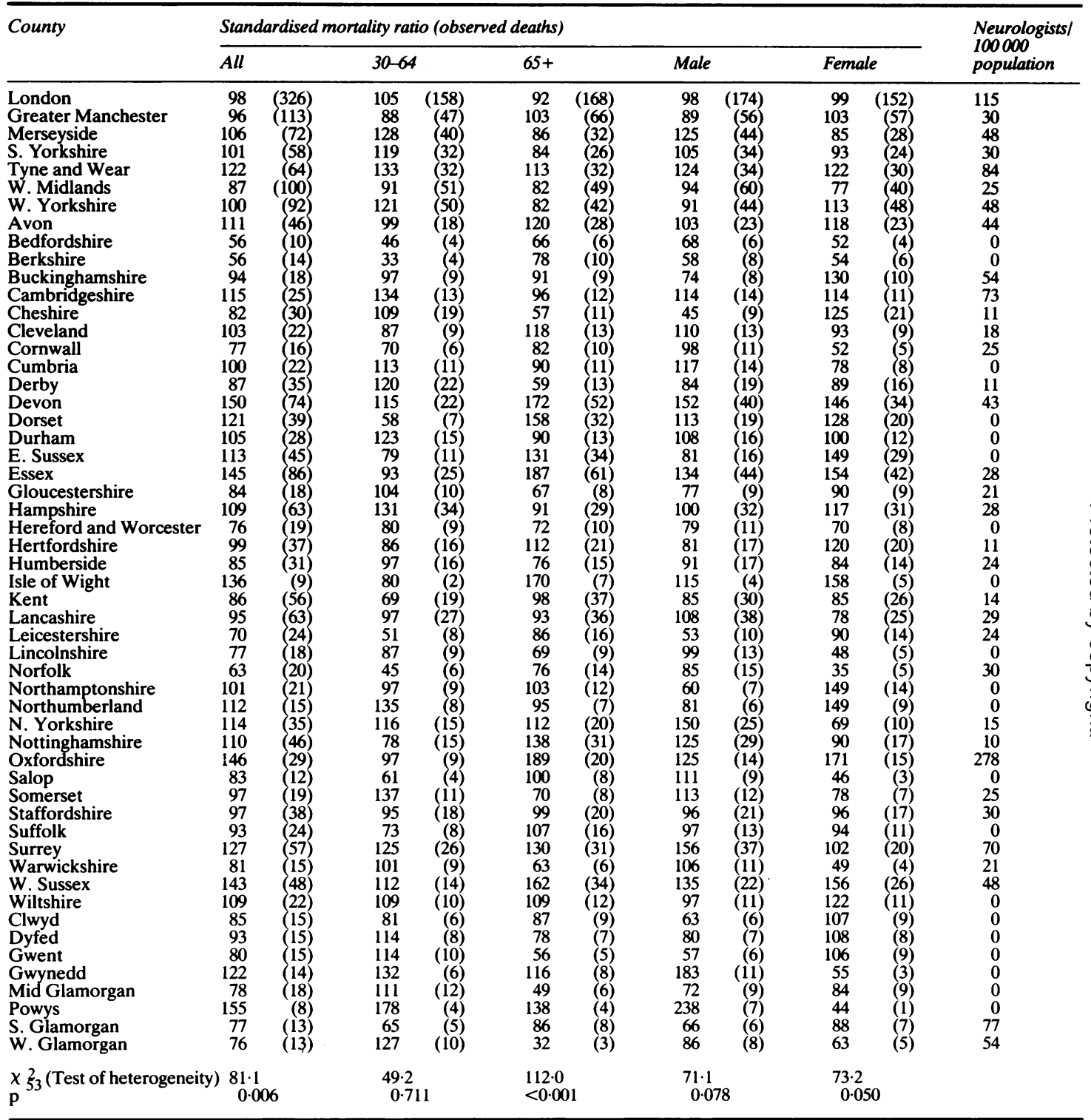

ogists (as determined by the addresses given by members of the Association of British Neurologists). Counter examples can be found however. West and South Glamorgan have low standardised mortality ratios despite having a considerable number of neurologists and in Powys and Dorset the reverse is true. Overall there was a slight, but non-significant, positive rank correlation (Kendall rank correlation coefficient $0 \cdot 13, p=0 \cdot 10$ ) between the rates of motor neuron disease in different counties and the number of neurologists per 100000 population in each county.

Differing standards of neurological diagnosis might be expected to have most effect on the rates among 


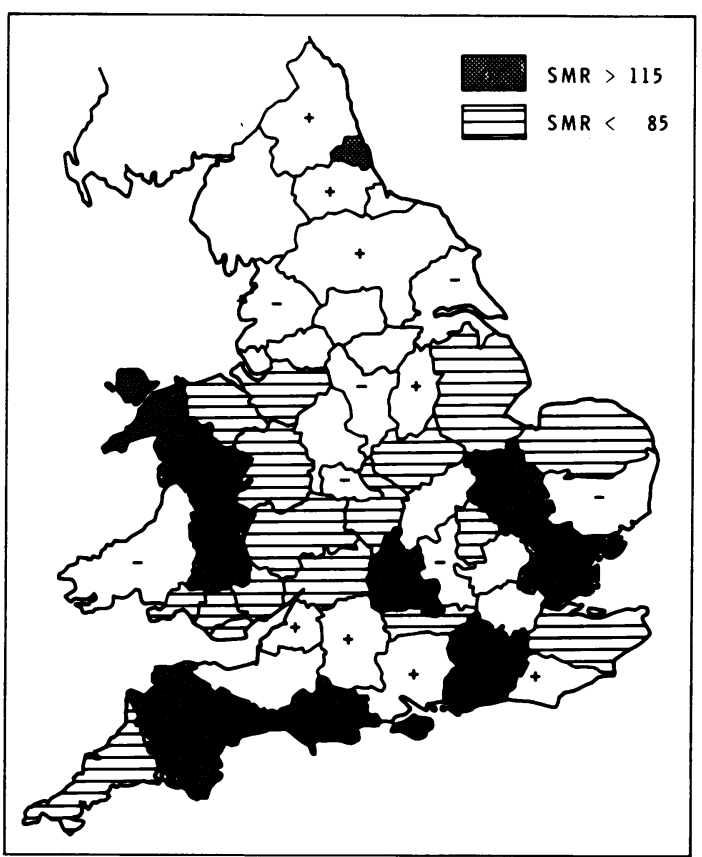

Fig 5 Counties of England and Wales with high (>115) or low $(<85)$ standardised mortality ratios $(S M R)$ for motor neuron disease 1975-7\%. Counties with marginally raised standardised mortality ratios (106-115) are indicated with a “+”, those marginally low (85-94) with a "-".

the elderly in whom the diagnosis may be obscured by other disorders and the general frailties of old age. The figures in table 1 for those aged 64 years old lend weight to this explanation. The heterogeneity in the standardised mortality ratios between counties seems, for the most part, to be due to variations in ratios among those over the age of 64 years. The variation between counties for deaths among those aged $30-64$ years was very close to that which might be expected to have arisen by chance. However, the number of neurologists per 100000 population in each county was less correlated with the standardised mortality ratios for those aged over 64 years than it was for all cases (correlation coefficient $r=0 \cdot 10, p=$ $0 \cdot 17)$.

There was no appreciable difference in the heterogeneity of the standardised mortality ratios between counties for males and females and there was a statistically significant correlation between the standardised mortality ratios for males and females by county $(r=0.39, p<0 \cdot 02)$.

Each county is made up of several districts (or municipal boroughs) and the variation observed in the standardised mortality ratios across the 381 districts and boroughs of England and Wales was

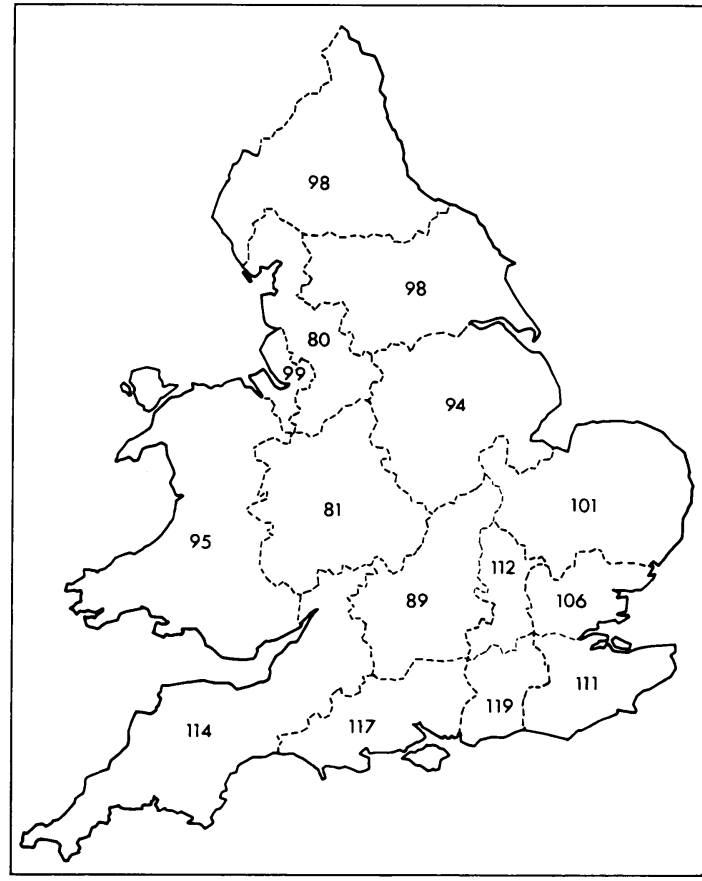

Fig 6 Standardised mortality ratios for motor neuron disease in the 15 Hospital Regions of England and Wales (1963-73).

statistically significant $(\mathrm{p}<0.05)$. However, the variation between districts within counties was not significant $(\mathrm{p}=0.12)$ indicating that the heterogeneity of the ratio between districts might be explained by variations in disease rates over larger areas.

Data were also available on motor neuron disease death rates by Hospital Region for the period 19631973 and fig 6 shows the 15 Hospital Regions and their standardised mortality ratios. The high motor neuron disease mortality ratios of the southern coastal regions and the below average rates in the Midlands were again apparent over this longer and earlier time period, confirming in general terms the impression gained from fig 5 . The standardised mortality ratios shown in fig 6 were based on between 219 and 571 deaths per Hospital Region and are thus more reliable than those given in table 1 and the heterogeneity of the standardised mortality ratios between regions was highly significant $(p<0.001)$.

The variation between hospital regions in standardised mortality ratios among those aged 30-64 years was statistically significant $(p<0.001)$ but the variation was much less than in those aged 65 years and over. The variation in the standardised mortality 
Table 2 Standardised mortality ratios for each Hospital Region for all motor neuron disease deaths during 1963-73 and subdivided by age and sex. Observed deaths are given in brackets

\begin{tabular}{|c|c|c|c|c|c|}
\hline \multirow[t]{2}{*}{ Hospital Region } & \multicolumn{5}{|c|}{ Standardised mortality ratio (observed deaths) } \\
\hline & All & $30-64$ & $65+$ & Male & Female \\
\hline$x_{14}^{2}\left(\begin{array}{l}\text { Test of } \\
\text { heterogeneity })\end{array}\right.$ & $\begin{array}{l}108.2 \\
<0.001\end{array}$ & $\begin{array}{l}33.3 \\
<0.001\end{array}$ & $\begin{array}{l}112.0 \\
<0.001\end{array}$ & $\begin{array}{l}49.0 \\
<0.001\end{array}$ & $\begin{array}{l}69.3 \\
<0.001\end{array}$ \\
\hline
\end{tabular}

Table 3 Standardised mortality ratios by social class for 15-64 year old men dying of motor neuron disease in 1970-72

\begin{tabular}{|c|c|c|c|c|}
\hline \multirow[t]{2}{*}{ Social class } & & \multicolumn{2}{|l|}{ Deaths } & \multirow{2}{*}{$\begin{array}{l}\text { Standardised } \\
\text { mortality } \\
\text { ratio }\end{array}$} \\
\hline & & Observed & Expected & \\
\hline $\begin{array}{l}\text { I. } \\
\text { II. } \\
\text { III.N } \\
\text { III.M } \\
\text { IV. } \\
\text { V. }\end{array}$ & $\begin{array}{l}\text { Professional } \\
\text { Intermediate } \\
\text { Skilled (non-manual) } \\
\text { Skilled (manual) } \\
\text { Partly skilled } \\
\text { Unskilled }\end{array}$ & $\begin{array}{r}20 \\
98 \\
74 \\
230 \\
98 \\
43\end{array}$ & $\begin{array}{r}23 \cdot 8 \\
110 \cdot 1 \\
61.2 \\
198 \cdot 3 \\
107.7 \\
48.9\end{array}$ & $\begin{array}{r}84 \\
89 \\
121 \\
116 \\
91 \\
88\end{array}$ \\
\hline v. & Total & 563 & 550 & \\
\hline
\end{tabular}

$x_{5}^{2}=10 \cdot 71(p<0 \cdot 10)$

ratios among females was a little greater than that among males (table 2).

\section{Occupation}

Table 3 shows the standardised mortality ratio for each social class in 1970-72. The highest rates were in skilled workers, and the lowest in professional and unskilled workers but the variation in the standardised mortality ratios between the different social class groupings was not statistically significant.

The standardised mortality ratios for Occupation Orders $\mathrm{I}-\mathrm{XXV}^{13}$ are given in table 4 , ranked by the standardised mortality ratios. The observed and expected deaths are pooled from the figures for 15-64 year old men in 1970-72 and 30-74 year old men in 1975: reliable data for $1970-72$ on the former occupation of retired men aged 65-74 were unavailable. The excess of motor neuron disease deaths in leather workers is not particularly remarkable in itself, being based on just nine deaths, but this occupation had the highest standardised mortality ratio in both $1970-72$ (six deaths, standardised mortality ratio $=259$ ) and 1975 (three deaths, standardised mortality ratio $=200$ ). "Leather workers" includes the Occupation Units ${ }^{13} 060$ (tanners; leather, fur dressers and fellmongers), 061 (shoemakers and repairers), 062 (cutters, lasters, sewers, footwear and related workers) and 063 (leather product makers, not elsewhere classified) but there were insufficient deaths to study the Units separately. The second Order in table 2, clothing workers, includes tailors and upholsterers who might also come in contact with leather, and "makers of light leather products". Hawkes and Fox ${ }^{15}$ reported the increase in motor neuron disease deaths in leather workers in 1970-72 and provided figures for 1959-63 (nine deaths, 5.97 expected). Combining all the available data, there is a significant excess of deaths from motor neuron disease in leather workers (18 deaths, 9.79 expected: $\left.\chi_{1}^{2}=6.88, p<0.01\right)$.

It was also possible to examine the standardised mortality ratios in 1975 of women classified by their husbands occupation. The largest standardised mortality ratio was in women married to "leather 
Table 4 Occupation Orders I-XXV listed in order of decreasing standardised mortality ratio for motor neuron disease (NEC is an abbreviation of "not elsewhere classified")

\begin{tabular}{|c|c|c|c|c|}
\hline \multicolumn{2}{|c|}{ Occupation Order } & \multicolumn{2}{|l|}{ Deaths } & \multirow{2}{*}{$\begin{array}{l}\text { Standardised } \\
\text { mortality } \\
\text { ratio }\end{array}$} \\
\hline & & $\begin{array}{c}\text { Observed } \\
9\end{array}$ & $\begin{array}{c}\text { Expected } \\
3.82 \\
4.63\end{array}$ & \\
\hline $\begin{array}{r}\text { IX } \\
\text { XI } \\
\mathbf{V} \\
\text { X } \\
\text { XVI } \\
\text { XII } \\
\text { XXV } \\
\text { XIX } \\
\text { VII } \\
\text { XXII } \\
\text { XIII } \\
\text { II } \\
\text { VIII } \\
\text { XXI } \\
\text { VI } \\
\text { XXX } \\
\text { XXIII } \\
\text { XVIII } \\
\text { XXIV } \\
\text { I } \\
\text { XIV } \\
\text { IV } \\
\text { XVII } \\
\text { III }\end{array}$ & $\begin{array}{l}\text { Leather workers } \\
\text { Clothing workers } \\
\text { Construction workers } \\
\text { Furnace forge, foundry, rolling mill workers } \\
\text { Textile workers } \\
\text { Painters and decorators } \\
\text { Food, drink and tobacco workers } \\
\text { Professional technical workers, artists } \\
\text { Transport and communications workers } \\
\text { Engineering and allied trades workers, NEC } \\
\text { Sales workers } \\
\text { Paper and printing workers } \\
\text { Mines and quarrymen } \\
\text { Woodworkers } \\
\text { Clerical workers } \\
\text { Electrical and electronic workers } \\
\text { Warehousemen, storekeepers, packers and bottlers } \\
\text { Service, sport and recreation workers } \\
\text { Labourers NEC } \\
\text { Administrators and managers } \\
\text { Farmers, forester and fishermen } \\
\text { Makers of other products } \\
\text { Glass and ceramic makers } \\
\text { Drivers of stationary engines } \\
\text { Gas, coke and chemical workers }\end{array}$ & $\begin{array}{r}9 \\
7 \\
43 \\
12 \\
10 \\
20 \\
17 \\
84 \\
82 \\
127 \\
76 \\
11 \\
25 \\
21 \\
65 \\
17 \\
32 \\
53 \\
56 \\
44 \\
31 \\
7 \\
2 \\
11 \\
4\end{array}$ & $\begin{array}{r}3.82 \\
4.63 \\
31.59 \\
9.25 \\
7.88 \\
15.96 \\
13.80 \\
71.35 \\
70.99 \\
112.22 \\
67.58 \\
9.97 \\
22.95 \\
19.23 \\
64.87 \\
18.08 \\
35.67 \\
58.62 \\
68.76 \\
54.05 \\
39.99 \\
9.05 \\
3.34 \\
18.54 \\
7.06\end{array}$ & $\begin{array}{l}236 \\
151 \\
136 \\
130 \\
127 \\
125 \\
123 \\
118 \\
116 \\
113 \\
112 \\
110 \\
109 \\
109 \\
100 \\
94 \\
90 \\
90 \\
81 \\
81 \\
78 \\
77 \\
60 \\
59 \\
57\end{array}$ \\
\hline
\end{tabular}

Table 5

\begin{tabular}{|c|c|c|c|c|}
\hline Region & Population & Year of study & Cases & $\begin{array}{l}\text { Average annual } \\
\text { incidence } \\
\text { per } 100000\end{array}$ \\
\hline
\end{tabular}

workers" with three deaths and 0.80 expected (standardised mortality ratio $=375, \mathrm{p}<0.05$ ).

\section{Discussion}

The uniformity of motor neuron disease incidence rates around the world has been noted previously. 16 Apart from two remarkable foci in the Western Pacific, Guam ${ }^{17}$ and the Kii Peninsular of Japan, 18 where the incidence of motor neuron disease is approximately 50 times higher than elsewhere, incidence rates are close to 1.0 per 100000 everywhere (table 5). Some of the variation in rates arises from the different age structures of the populations studied and the lowest rates are generally reported in underdeveloped countries ${ }^{24}$ where there may be both under-diagnosis and under-reporting.

The majority of patients with motor neuron disease die of the disease, so that mortality rates should approximate incidence rates. Juergens et $\mathrm{al}^{19}$ reported that 30 of 33 deceased patients in Rochester, Minnesota, over the period 1925-1977 had motor neuron disease listed as a cause of death. This is similar to our findings of cases from Oxfordshire and Berkshire, where 49 of 56 patients known to have died with motor neuron disease had the disease given as the underlying cause. The diagnosis of motor neuron disease was fairly certain in these cases, and it is likely that a higher percentage of patients with atypical forms of motor neuron disease would have death attributed to some other cause. We are not in a position to assess the degree to which death from other neurological disease are erroneously attributed to motor neuron disease.

The age-adjusted mortality rate in England and Wales has increased from 1.2 per 100000 in 1959-61 
to 1.6 in 1977-79. Similar increases have been reported elsewhere, ${ }^{25}$ but it is not clear how much of the increase can be attributed to improved standards of diagnosis and death certification and how much, if any, reflects an increase in incidence of motor neuron disease. Rates have risen most in the elderly of both sexes as might be expected if the disease was being diagnosed more reliably but it is difficult to explain why the increase among 45-64 year olds should be seen only in women.

The graph of the age-specific mortality rates (fig 1) also suggests that the diagnosis might be missed after the age of 65 years: a steep rise from age 45 to 65 years abruptly tails off and the mortality rate for those aged 75 and over is less than that for $65-69$. The same age pattern has been reported elsewhere.1719212526 The sex ratio is also remarkably similar in different parts of the world, being close to $1 \cdot 6: 1$ (male to female) in most series. ${ }^{19-21} 2526$

Given the similarity of incidence, secular trends, age distribution and sex ratio in countries with widely differing health care systems and death certification practices, it is perhaps rather surprising that we have found significant variations within England and Wales. Nevertheless the excess of motor neuron disease deaths seen in the southern counties, and the low mortality in the Midlands, are unlikely to have arisen by chance. The differences between counties are quite large, the standardised mortality ratio ranging from 56 in Bedfordshire and Berkshire to 155 in Powys but there were too few cases in most counties to provide reliable estimates. The standardised mortality ratios varied much less by Hospital Region from 80 in Manchester to 119 in SW Metropolitan. For both analyses it was clear the variation was largely attributable to deaths occurring among those aged over 65 years, which suggests that the low ratios might be a consequence of underdiagnosis of the disease. There was no clear-cut relationship between the motor neuron disease mortality of a county and the number of neurologists there, but a head-count of neurologists is a very crude measure of the availability of specialist neurological care in an area as many neurologists in the major centres such as London, Oxford and Newcastle conduct clinics in adjacent counties.

The southern coastal towns are popular retirement areas and perhaps the onset of motor neuron disease prompts some patients to move to these areas. It would seem unlikely however that this migration could account for more than a small proportion of the observed excess of motor neuron disease deaths.

There was no evidence for gecgraphical clustering of the disease on a finer scale than by county: the variation between districts within counties was no greater than expected by chance. This suggests that whatever is the reason for the variation in disease rates in England and Wales, it is acting over quite large areas rather than in localised areas.

Several putative aetiological factors are occupation related. These include heavy labour, pneumatic drilling, trauma, repeated minor electric shocks and exposure to lead, organic compounds of mercury and benzol. In this study only two occupations had a significant excess of deaths-leather workers and construction workers. In neither case was the signifcance very high but other evidence suggests that the excess in leather workers might be genuine. The standardised mortality ratio for leather workers was highest of all Occupation Orders in both 1970-72 and 1975 and was also high in 1959-63. The second Order in table 4, clothing workers, also includes some leather workers, and the wives of leather workers had a marginally significant excess of motor neuron disease deaths. There have been a number of reports in the literature linking motor neuron disease to exposure to animals: a preliminary report of a large Los Angeles-based case-control study 26 stated that the only clue to an aetiological agent was a greater frequency of exposure to animal carcasses and hides among cases, and the only significant associations in a case-control study in Guam were exposure to certain animals and consumption of raw meat. Farmers have been reported to have an increased risk of motor neuron disease ${ }^{21}$ but other studies 82728 have failed to confirm this finding and we found no excess motor neuron disease amongst farmers (table 4).

The independent associations of leather working and motor neuron disease in 1959-63,1970-72 and 1975 make it unlikely to be a chance observation. Systematic biases, such as would occur if the number of men employed in the leather industry was substantially undercounted at the censuses, could explain the high standardised mortality ratios but as other cause-specific mortality rates and overall mortality would be overestimated by the same factor the error would be easily detected. It is difficult to judge how far an association such as this should be pursued. Kondo 25 listed eight toxins, nine forms of trauma (including surgery) and five miscellaneous factors that have been reported by others to be associated with motor neuron disease, although admittedly most were based on very limited evidence. It could be argued that, with so little known about the aetiology of motor neuron disease, any lead is worth following. In this instance the association is with a relatively uncommon occupation-only 2-3 motor neuron disease deaths occur each year in leather workers-making further research very difficult and, if the cause of the excess fails to throw light on the aetiology of the other $99 \%$ of cases in the community, the research will have proved rather unprofitable. 
The authors thank Mrs R Carleshi of the Office of Population Censuses and Surveys for her assistance with data from that office, and Dr A Adelstein for his advice and encouragement. We are also grateful to the Director and staff of the Oxford Record Linkage Study for their assistance and to the physicians who allowed us access to their clinical records.

JB was supported by an Applied Health Sciences Fellowship from the Australian National Health and Medical Research Council.

\section{References}

1 Campbell AMG, Williams ER, Barltrop D. Motor neurone disease and exposure to lead. J Neurol Neurosurg Psychiatry 1970;33:877-85.

2 Kantarjian AD. A syndrome clinically resembling amyotrophic lateral sclerosis following chronic mercurialism. Neurology (Minneap) 1961;11:639-44.

3 Yase $Y$. The pathogenesis of amyotrophic lateral sclerosis. Lancet 1972;ii:292-6.

${ }^{4}$ Kilness AW, Hochberg FH. Amyotrophic lateral sclerosis in a high selenium environment. JAMA 1977;237:2843-4.

5 Alpers BJ, Farmer RA. Role of repeated trauma by pneumatic drill in production of amyotrophic lateral sclerosis. Arch Neurol 1949;62:178-82.

6 Breland AE, Currier RD. Multiple sclerosis and amyotrophic lateral sclerosis in Mississippi. Neurology (Minneap) 1967;17:1011-6.

${ }^{7}$ Kondo K, Tsubaki T. Case-control studies of motor neuron disease. Association with mechanical injuries. Arch Neurol 1981;38:220-6.

${ }^{8}$ Kurtzke JF, Beebe GW. Epidemiology of amyotrophic lateral sclerosis. I. A case-control comparison based on ALS deaths. Neurology (Minneap) 1980;30:453-62.

${ }^{9}$ Haynal A, Regli F. Zusammenhang der amyotrophischen lateralsklerose mit gehanften Elektrotraumata. Confin Neurol 1964;24:189-98.

10 Ask-Upmark E. Precipitating factors in the pathogenesis of amyotrophic lateral sclerosis. Acta Med Scand 1961;170:717-23.

11 Norris FH, Engel WK. Carcinomatous amyotrophic lateral sclerosis. In: Brain WR, Norris FH, eds, The Remote Effects of Cancer on the Nervous System. New York: Grune and Stratton, 1965:24-34.

12 Mulder DW, Rosenbaum RA, Layton DD. Late progression of poliomyelitis or forme fruste amyotrophic lateral sclerosis. Mayo Clin Proc 1972;47:756-61.
13 Office of Population Censuses and Surveys. Occupational mortality: decennial supplement 1970-72. London: HMSO, 1978.

14 Ohno Y, Aoki K, Aoki N. A test of significance for geographic clusters of disease. Int $J$ Epidemiol 1979;8:273-81.

15 Hawkes $\mathrm{CH}$, Fox J. Motor neurone disease in leather workers. Lancet 1981;i:507.

16 Kurland LT. Epidemiologic investigations of amyotrophic lateral sclerosis. III. A genetic interpretation of incidence and geographic distribution. Proc Mayo Clin 1957;32:449-62.

17 Reed DM, Brody JA. Amyotrophic lateral sclerosis and Parkinsonism-dementia on Guam 1945-1972. I. Descriptive epidemiology. Am J Epidem 1975;101: 287-301.

18 Yase Y. VII. Neurologic diseases in the Western Pacific Islands, with a report on the focus of amyotrophic lateral sclerosis found in the Kii Peninsula, Japan. Am J Trop Med Hyg 1970;19:155-66.

19 Juergens SM, Kurland LT, Okajaki H, et al. ALS in Rochester, Minnesota 1925-1977. Neurology (Minneap) 1980;30:463-70.

20 Gudmundsson KR. The prevalence of some neurological diseases in Iceland. Acta Neurol Scand 1968;44:57-69.

21 Rosati G, Pinna L, Granieri E, et al. Studies on epidemiological, clinical and etiological aspects of ALS disease in Sardinia, southern Italy. Acta Neurol Scand 1977;55:231-44.

22 Lorej A. Ein Beitrag zu Klinik und Vorkommen der amyotrophischen Lateralsklerose (isolierte und familiare Falle). Schweiz Med Wochenschr 1969;99:517.

23 Matsumoto N, Worth RM, Kurland LT, et al. Epidemiologic study of amyotrophic lateral sclerosis in Hawaii: Identification of high incidence among Filipino men. Neurol (Minneap) 1972;22:934-40.

24 Olivares L, San Esteban E, Alter M. Mexican "resistance" to amyotrophic lateral sclerosis. Arch Neurol 1972;27:397-402.

25 Kondo K. Motor neuron disease: changing population patterns and clues for etiology. Adv Neurol 1978;19:509-43.

26 Jokelainen M. The epidemiology of amyotrophic lateral sclerosis in Finland. J Neurol Sci 1976;29:55-63.

27 Hanisch R, Dworsky RL, Henderson BE. A search for clues to the cause of amyotrophic lateral sclerosis. Arch Neurol 1976;33:456-7.

28 Palo J, Jokelainen M. Geographic and social distribution of patients with amyotrophic lateral sclerosis. Arch Neurol 1977;34:724. 
${ }^{2}$ Meyer et al. Progressive change in cerebral blood flow during the first three weeks after subarachnoid haemorrhage. Neurosurgery 1983;12:58-76.

\section{Maurice-Williams replies:}

I have carefully re-read the article concerned and I cannot see that I have misquoted it in my previous comment on the letter of Mr Scharr and Mr Neil-Dwyer. The subsequently published article does indeed report that administration of tranexamic acid appears to be associated with a fall in cerebral blood flow during the second week after subarachnoid haemorrhage. If this is confirmed it will clearly have very important implications with regard to the effect of anti-fibrinolytic drugs on patients with ruptured aneurysms: However it does not resolve the main point that I had hoped to get across in the paper that is the subject of this discussionnamely the differing time courses of confirmed re-bleeds and episodes of nonhaemorrhagic deterioration and the fact that the time course of the latter coincides with the time course of rebleeding as reported in earlier studies, suggesting that those studies may have confused these two events and thus significantly overestimated the incidence of early rebleeding.

\section{Notices}

The Commonwealth Association for Mental Handicap and Developmental Disabilities (CAMHDD) has recently been formed with the support of a launching grant from the Commonwealth Foundation and has as its principal aims the prevention and amelioration of mental handicap and related developmental disabilities in developing Commonwealth countries. It is hoped that its membership ultimately will be that of individual professional and non-professional workers either working within developing countries in the field of mental handicap or those in developed countries that have a particular interest in this field in such countries. It is hoped to establish ultimately a form of directory of interested workers and from time to time practically orientated workshops will be held in differing developing countries. Further details may be obtained from the Association's UK Representative: Dr Gwilym Hosking, Consultant Paediatric Neurologist, The Ryegate Centre, Children's Hospital, Sheffield S10 5DD, UK.

Symposium on Brain Metabolism. The Eleventh International Symposium of the Fulton Society on Brain Metabolism will be held on 2 October, 1983 in New Orleans, USA associated with the 108th Annual Meeting of the American Neurological Association. Details may be obtained from Professor Dr Victor Soriano, Calle Buenos Aires 363, Montevideo, Uruguay.

\section{Correction}

Motor Neuron Disease in England and Wales, 1959-1979 (J Neurol Neurosurg Psychiatry 1983;46:197-205)

The authors wish to correct the figures in the last column of table 1 , where the values for "Neurologists 100,000 population" were too high by a factor of 100 . Thus, for example, the figure for London should have been $1 \cdot 15$, for Greater Manchester $0 \cdot 30$. 